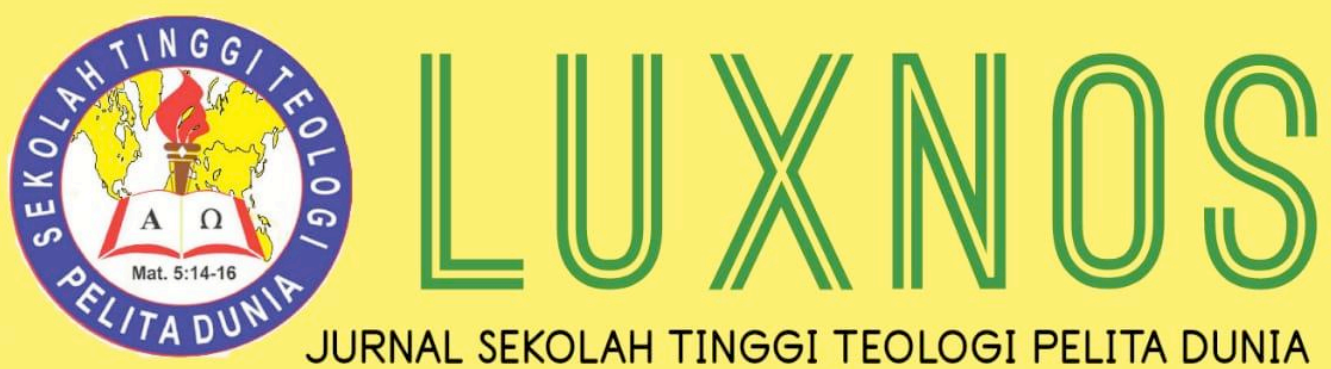

Volume 7 Nomor 2, Desember 2021

\title{
Pedagogi Pohon (Jarak): Metode Pedagogi dalam Peristiwa Pohon Jarak Yunus 4
}

\author{
Yane Octavia Rismawati Wainarisi \\ Institut Agama Kristen Negeri (IAKN) Palangka Raya \\ yaneoctavia@gmail.com
}

\begin{abstract}
There are some method of study. One of those method is Pedagogy. Pedagogy is used as a unique method in learning not only as a cognitive aspect but psychomotoric and affective especially in spiritual aspect. This approach is a very important method in Educational Proccess so do Indonesian Government insert it in the one kind of educational meaning. from the Theological insight, Pedagogical model being an important criteria for a Christian lecturer to transform student target characteristic. The Bible especially old Testament give many model in Pedagogy which can observe from the first creaturing of human. Therefore, the author use the effort of God to transform Jonah Character from his experience with the castor oil plant which I call Castor-Oil Plant Pedagogy. This research made to observe God Pedagogical model to Jonah so do Jonah could have a better knowledge about God's love for the world which unlimited for one nation only. Castor-oil Plant Pedagogy fill with God's unique method to transform Jonah's Character by his experience meeting with the plant. This research made by explorative cualitative method dan narrative critique to various library related to Pedagogy and the Book of Jonah.
\end{abstract}

Keywords: castor-oil plant, Education, Jonah, Niniveh, Pedagogy

\begin{abstract}
Abstrak: Ada berbagai macam metode dalam pembelajaran, salah satunya adalah pedagogi. Pedagogi digunakan sebagai metode khusus dalam pembelajaran bukan hanya dalam aspek kognitif dan pikomotorik namun juga afektif terutama dalam hal spiritual. Pentingnya pendekatan ini dilakukan dalam Pendidikan sehingga pemerintah Indonesia secara resmi memberikan pengertian khusus terhadap istilah pedagogi ini. Dari sisi Teologis, model pengajaran Pegagogis ini menjadi kriteria penting seorang pendidik Kristen dalam mentransformasi karakter siswa target. Alkitab terutama Perjanjian Lama memberi berbagai model Pedagogi dan bila diselidiki model ini sudah ada sejak manusia diciptakan. Dari sekian banyak model tersebut, penulis mengangkat upaya Allah dalam mentransformasi karakter Yunus melalui pengalamannya dengan Pohon Jarak yang penulis sebut dengan Pedagogi Pohon Jarak. Tujuan dari penelitian ini adalah untuk mengkaji model pedagogi Allah terhadap Yunus agar Yunus mengenal tentang Allah dan tujuan kasih Allah bagi seluruh dunia yang tidak terbatas pada satu umat saja. Pedagogi Pohon Jarak berisi metode unik yang Allah gunakan untuk mentransformasi karakter Yunus melalui
\end{abstract}


Volume 7 Nomor 2, Desember 2021

pengalaman pertemuannya dengan pohon jarak. Penelitian ini dibuat dengan metode kualitatif eksploratif dan kritis narasi melalui penelitian terhadap berbagai Pustaka yang berkaitan dengan pedagogi dan kitab Yunus.

Kata Kunci: Niniwe, Pedagogi, Pendidikan, Pohon Jarak, Yunus.

\section{Pendahuluan}

Proses Pendidikan bukanlah sebuah isu baru yang muncul setelah era modern. Pendidikan sudah ada bahkan sejak awal manusia ada di muka bumi. Pada mulanya, Allah berperan sebagai guru, pelatih, pendamping pertama yang mengajar seluruh dunia tentang Diri-Nya. Ada banyak metode dalam mengajar yang Allah gunakan dalam mendidik manusia. Hal ini tersirat dalam Perjanjian Lama yang didapat dari relasi antara Allah dengan manusia, manusia dengan sesamanya dan manusia dengan alam semesta. Salah satu dari proyek pendidikan yang Allah lakukan tergambar dari sepenggal kisah Yunus bersama dengan pohon jarak sebagai upaya pedagogis Allah dalam mentransformasi karakter Yunus. Kisah ini bertujuan untuk memberi gambaran pedagogis bagaimana penulis kitab memberi kritik terhadap ekslusivisme orang-orang Israel yang tidak mau berbagi kasih Allah kepada bangsa lain. Ada banyak penelitian yang sudah dilakukan terhadap kitab Yunus yang berpijak terutama dari sisi Misiologi. Penelitian ini terutama berpijak pada pendidikan sebagai gambaran pedagogis dalam proses pendidikan karakter Kristen. Dasar dari penelitian ini adalah proses transformasi karakter melalui pengalaman pertemuan Yunus dengan pohon jarak yang penulis angkat dalam judul Pedagogi Pohon Jarak.

\section{Metode Penelitian}

Tulisan ini menggunakan metode kualitatif eksploratif dan kritik narasi. Metode penelitian kualitatif merupakan metode penelitian yang berlandaskan pada filsafat positivisme. Untuk artikel ini, penulis menggunakan kajian Pustaka terhadap beberapa buku Perjanjian Lama dan berbagai buku yang berkaitan dengan Pedagogi. ${ }^{1}$ Dari buku-buku tersebut, penulis melakukan tindakan eksploratif yang dijabarkan dalam tulisan namun tanpa bermaksud mencari kebenaran fakta. ${ }^{2}$ Sementara itu, penelitian eksploratif merupakan penelitian yang digunakan terhadap suatu isu yang belum memiliki data-data baku sebelumnya, ${ }^{3}$ yaitu penggunaan istilah "Pedagogi Pohon Jarak" yang menjadi isu utama dari tulisan ini.

${ }^{1}$ Sugiyono, Metode Penelitian Kuantitatif, Kualitatif, Dan R \& D (Bandung: Alfabeta, 2013), Np.

2 Subandi, "Qualitative Description as One Method in Performing Arts Study," Harmonia, no. 19 (2011), 173-179.

3 Morissan, Metode Penelitian Survei (Rawamangun: Kencana, 2012), Np. 
Selain itu, penulis juga menggunakan pendekatan kritik naratif untuk mengeksplorasi narasi dalam kitab Yunus dengan asumsi awal bahwa kitab ini berisi narasi tentang seorang nabi. Kritik naratif merupakan sebuah pendekatan yang digunakan dalam menganalisis narasi Alkitab untuk mengkomunikasikan berbagai bentuk cerita dalam Alkitab kepada para pembacanya. ${ }^{4}$ Kritis naratif ini secara umum bergerak dari titik masalah dalam suatu cerita kepada rekonsiliasi dari kisah tersebut. 5 Namun demikian, ada berbagai jenis kisah dalam Alkitab yang berisi kesaksian pribadi, sejarah-sejarah suci, kisah-kisah fiksi, dll. ${ }^{6}$ Untuk itu, perlu kritis untuk memilah kisah-kisah yang ada, pengarang asli atau tidak, alur cerita, penokohan, sudut pandang, latar belakang cerita, sampai kepada amanat yang ingin disampaikan. ${ }^{7}$ Analisis naratif menjadi cara penting dalam menafsirkan kitab Yunus karena pada dasarnya, kitab ini memang berisi kisah tentang seorang nabi yang tidak taat kepada Allah. ${ }^{8}$

\section{Hasil Pembahasan}

\section{Kompetensi Pedagogi Tenaga Pendidik}

Pedagogi berasal dari Bahasa Yunani paidos yang berarti anak dan agogos yang berarti membimbing. Dengan demikian, secara harfiah kata pedagogi berarti membimbing anak atau pembimbingan terhadap anak. Pedagogi berkaitan dengan metode dan teori mengajar dan seringkali juga menggambarkan tentang seorang guru yang memberikan perhatian mendalam pada peraturan-peraturan formal. ${ }^{9}$ Menurut UU No. 14 tahun 2005, kompetensi Pedagogi adalah kemampuan mengelola pembelajaran peserta didik. Pedagogi sendiri merupakan satu dari empat macam kompetensi yang harus dimiliki oleh seorang guru maupun dosen atau seluruh tenaga pendidik tepatnya. Berdasarkan UU No. 14 tahun 2005, kompetensi-kompetensi tersebut antara lain: kompetensi pedagogi, kompetensi kepribadian, kemampuan sosial, dan kompetensi personal. ${ }^{10}$

Silitonga mengutip Payong dan Sulfemi dengan menyebut pedagogi adalah segala sesuatu yang dilakukan oleh pendidik untuk membimbing karakter muridmuridnya untuk menjadi dewasa (Permana, 2020). Berbeda dengan pendekatan

\footnotetext{
4 Peter S. Williamson, Catholic Principles for Interpreting Scripture, Catholic Biblical Quarterly, vol. $65,2003$.

5 David Jobling, The Sense of Biblical Narrative: Structural Analyses in the Hebrew Bible II (England: Sheffield Academic Press, 1987), Np.

${ }^{6}$ Robert Alter, The Art of Biblical Narrative (New York: basic Books, 2010), Np.

7 Williamson, Catholic Principles for Interpreting Scripture, vol. 65, p.

${ }^{8}$ Leslie C Allen, The Books of Joel, Obadiah, Jonah, and Micah (Grand Rapids: Wm. B. Eerdmans Publishing, 1976), Np.

9 Rahmat Permana, Teori Dan Praktik Pendidikan Jasmani Di Perguruan Tinggi (Tasikmalaya: Edu Publisher, 2020), Np.

10 Ibid, Np.
} 
Pendidikan pada umumnya, kompetensi pedagogi tidak hanya membutuhkan aspek profesionalitas dalam penyelenggaraan Pendidikan namun ikut terlibat dalam pembangunan mental, karakter, dan perilaku para peserta didik. ${ }^{11}$ Dalam hal ini seorang pendidik tidak hanya berperan dalam menyampaikan dan mentransformasi pengetahuan dan pembelajaran, melainkan mengembangkan kepribadian para murid. Target akhir pedagogi adalah memanusiakan manusia.

Pendekatan pedagogi lebih berfokus terhadap cara penyampaian bimbingan lewat berbagai aktifitas khusus yang lebih efektif dan efisien dibanding ceramah atau nasihat. Guru dalam pedagogi berperan mengembangkan mental dan nurani anak sehingga anak sensitif dengan soal-soal kemanusiaan, harkat dan derajat manusia dan menghargai sesamanya manusia. ${ }^{12}$ Guru juga berperan dalam mengembangkan keterampilan anak untuk hidup dalam masyarakat sehingga mampu menghadapi segala persoalan kehidupan. ${ }^{13}$

Peraturan yang mengatur secara khusus tentang kompetensi ini terdapat dalam Permendiknas No. 16 tahun 2007 tentang standar kualifikasi akademik dan kompetensi guru. Ada tujuh aspek dan indikator kompetensi pedagogi, antara lain: pemahaman wawasan atau landasan Pendidikan, pemahaman terhadap peserta didik, pengembangan kurikulum atau silabus, perancangan pembelajaran, pelaksanaan pembelajaran yang mendidik dan dialogis, komunikasi dengan peserta didik, penilaian dan evaluasi belajar. ${ }^{14}$

Pedagogi pohon jarak yang penulis maksud dalam tema ini berkaitan erat dengan pengalaman pribadi dan dialog yang terjadi antara Allah dan Yunus. Dalam kitab ini dikisahkan tentang seorang nabi bernama Yunus yang lari dari panggilan Allah karena tahu karakter Allah yang Maha Pengasih dan pasti akan mengampuni jika suatu bangsa bertobat. Yunus tidak ingin agar Niniwe bertobat dan membuat Allah tidak jadi menghukum mereka. Yunus tetap ingin agar Niniwe dihukum sesuai dengan kejahatan mereka. Pohon jarak sebenarnya bukanlah Pedagogi pertama yang Allah lakukan untuk mentransformasi karakter Yunus. Pengalaman Yunus ditelan oleh ikan besar menjadi tragedi awal dalam hidupnya yang seharusnya memberi Yunus pelajaran besar dalam tranformasi karakter. Pada tahap ini Yunus berubah pikiran dari akhirnya mau berangkat ke Niniwe namun bukan untuk melakukan transformasi karakter sebagai guru pedagogi, melainkan berseru atau dalam bahasa aslinya berteriak (meneriaki) orang-orang Niniwe tentang kabar penghukuman. Hal ini tampak dari kata-kata Yunus dan emosi negatif yang terkandung di balik kata-

${ }^{11}$ Ibid, Np.

12 Direktorat GTK Pendidikan Dasar, Modul Belajar Mandiri Calon Guru Pegawai Pemerintah Dengan Perjanjian Kerja Pedagogi, 2021.

${ }^{13}$ Nurdyansyah and Eni Fariyatul Fahyuni, Inovasi Model, Nizmania Learning Center, 2016.

${ }^{14}$ Yuberti, Teori Pembelajaran Dan Pengembangan Bahan Ajar Dalam Pendidikan, 2014. 
Volume 7 Nomor 2, Desember 2021

katanya: "Empat puluh hari lagi, maka Niniwe akan ditunggangbalikkan." (Yun. 3:4). Pada tahap ini, pedagogi Allah terhadap Yunus masih harus berlanjut dan belum tercatat dialog langsung antara Allah dan Yunus. Dialog pengajaran terjadi pada kasus Pohon Jarak. Melalui Pedagogi pohon jarak ini, Allah ingin memberi analogi antara kasih Yunus terhadap pohon dan kasih Allah kepada Niniwe.

Adalah sesuatu yang sangat wajar ketika kesalahan dilakukan, maka hukuman menjadi akibatnya. Hal ini disebut dengan keadilan. Namun perlu untuk menyadari bahwa selalu ada faktor pemicu di balik terjadinya kesalahan itu. Fakta yang ditemukan dalam kitab Yunus adalah bahwa Subyek pertama meminta subyek kedua untuk melakukan sesuatu pada sebuah obyek, namun subyek kedua menolak. Polanya:

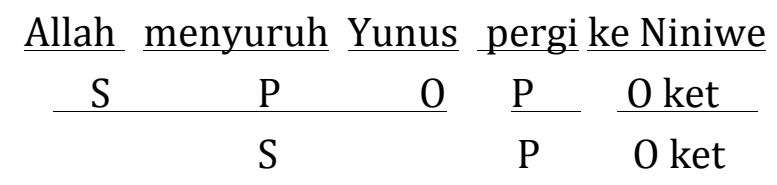

Yunus merupakan alat atau sarana yang dipakai Tuhan untuk menyampaikan maksud Tuhan kepada bangsa Niniwe. Allah ingin terjadi transformasi karakter terhadap orang-orang Niniwe dan Yunus bertugas menyampaikan pesan sehingga tranformasi karakter tersebut terjadi. Sementara inisiatif adalah dari Allah sendiri. ${ }^{15}$ Sebagai alat atau sarana yang digunakan dalam koridor tugasnya sebagai nabi atau penyampai pesan Allah, maka Yunus seharusnya bertugas untuk hanya menyampaikan semua yang Allah ingin katakan kepada manusia. Yunus dalam hal ini juga berperan untuk melakukan transformasi karakter terhadap orang-orang Niniwe sebagaimana yang dibahasakan oleh pengarang kitab Yunus sebagai bangsa yang "tidak tahu tangan kanan dan tangan kiri". Yunus bertugas untuk memberikan gambaran tentang mana yang "kanan" dan mana yang "kiri". Dengan demikian, orangorang Niniwe mengalami transformasi. Kontradiksi dengan tugasnya, Yunus justru menunjukkan emosi negatif terhadap orang-orang Niniwe.

Yunus memiliki prejudice yang buruk tentang Niniwe. Niniwe merupakan ibukota terakhir Asyur dan diperkirakan dibangun oleh Nimrod. ${ }^{16}$ Asyur sendiri pada zaman Yunus merupakan kerajaan baru yang ditakdirkan untuk membinasakan bangsa Israel. Bangsa ini merupakan bangsa yang ganas dan tidak sungkan untuk bertindak sewenang-wenang untuk bangsa yang dikalahkannya, tidak mengenal rasa belas kasihan, sundal dan kuat dengan magic. Sebenarnya Yunus sendiri tidak mengalami hal ini secara langsung, ia hanya mendengar dari nubuat-nubuat dan

\footnotetext{
${ }^{15}$ A. Th Kramer, Tafsiran Alkitab: Kitab Yunus (Jakarta: BPK Gunung Mulia, 2003), Np.

16 Ibid, Np.
} 
cerita nabi-nabi yang ada sebelumnya. Namun ini cukup bagi Yunus untuk memutuskan bahwa bangsa itu memang jahat dan mereka memang pantas untuk dihukum. Kejahatan mereka membuat Allah memutuskan untuk memusnahkan mereka dalam 40 hari dan hal ini sangat sesuai dengan bayangan Yunus. 40 hari merupakan waktu yang Allah berikan kepada Yunus untuk melakukan Pedagogi terhadap bangsa Niniwe. Namun ketika Allah memerintahkan Yunus untuk datang ke sana dan melakukan upaya Pedagogi melalui pewartaan pertobatan, Yunus lari dari panggilan tersebut. ${ }^{17}$ Yunus sangat membenci bangsa itu, dan di dalam dirinya memang sudah terdapat sentiment kebangsaan terhadap Niniwe.

Dalam analogi ini, Allah ingin mengajari Yunus tentang Kemahabesaran Kasih Allah kepada manusia yang tidak dapat dibatasi oleh siapapun. Kemahabesaran kasih Allah ini juga tidak dapat dibatasi oleh berbagai bentuk kesalahan yang diberikan kepada manusia. Yunus sebenarnya paham tentang hal ini namun ia mengeraskan hatinya dan bertindak sengaja agar tujuan Allah tidak tersampaikan kepada Niniwe. Akan tetapi, pada kenyataannya pandangan Allah berbeda dengan hati Yunus. Allah memiliki pikiran untuk mengampuni bangsa Niniwe. Dalam ayat 11 dituliskan bahwa bangsa itu merupakan bangsa yang besar dengan penduduk lebih dari seratus dua puluh ribu orang yang semuanya tidak dapat membedakan tangan kanan dan tangan kiri dengan ternaknya yang banyak. Tapi bukan itu saja alasan Allah untuk mengampuni orang Niniwe, tetapi karena sifat Dasar Allah yang Maha Kasih.

Secara berurutan teks pasal 4 kitab Yunus ditulis. Ayat 1: "Tetapi hal itu sangat mengesalkan hati Yunus, lalu marahlah ia." Secara etimologis, ada beberapa kata yang muncul tentang ayat 1 ini. Pertama melihat pada kata mengesalkan. Jika dari bahasa aslinya, maka arti katanya menjadi gemetar. Lalu kata marah, yang dari bahasa aslinya berarti jahat, sesuatu yang menular, yang sangat membahayakan, sangat jahat. Namun dalam versi lainnya muncul kata 'displeased Jonah exceedingly' yang berarti ketidaksenangan yang besar. Kata besar di sini berasal dari bahasa aslinya bahwa sesuatu itu besar atau sangat besar. Jadi bisa disimpulkan bahwa ketika melihat perubahan sikap Allah terhadap Niniwe, Yunus memandang hal itu sebagai hal yang jahat atau sesuatu yang membahayakan, yang merupakan kejahatan besar, sehingga ketika ia melihat hal itu, ia pun menjadi gemetar karena marah.

Dengan menggunakan beberapa perbandingan versi Alkitab, maka akan muncul kalimat-kalimat seperti: But it displeased Jonah exceedingly, and he was very angry (KJV), But this greatly displeased Jonah, and he grew angry (ML), This change of plans made Jonah very angry (LB), But it greatly displeased Jonah, and he became angry (NAS).

17 J Sidlow Baxter, Explore The Book: A Survey and Study of Each Book From Genesis (Grand Rapids: Zondervan, n.d.), Np. 
Volume 7 Nomor 2, Desember 2021

Pertobatan Niniwe (ps 3:5-10) menimbulkan kekesalan di hati Yunus. Pada versi Living Bible, jika diartikan maka akan muncul arti kalimat yang sedikit berbeda dengan versi lain yaitu perubahan rencana itu membuat Yunus sangat marah. Beberapa versi Alkitab menyampaikan keterangan tentang bagaimana bentuk kemarahan atau ketidaksenangan itu ini. KJV mengungkapkan bahwa ketidaksenangan (displeased) itu besar sekali (exceedingly), ML mengungkapkan bahwa kemarahan itu bertumbuh (grew) muncul dalam bentuk past tense, yang kirakira berarti bahwa apa yang Yunus lihat tentang Tuhan itu telah mengalami pertumbuhan dan kini sudah menjadi suatu kemarahan yang besar.

Ayat ke 2-3 menerangkan pengenalan Yunus terhadap karakteristik Allah. Yunus paham betul karakter Allah yang Maha Pengasih dan Penyayang, Panjang sabar dan berlimpah kasih setia serta yang menyesal dengan malapetaka yang hendak didatangkan-Nya. Namun pemahaman ini dibatasi oleh sentiment Yunus terhadap Niniwe sehingga Yunus menolak bersimpati dengan nasib yang akan menimpa bangsa itu. Ketika melihat Niniwe bertobat, Kramer menjelaskan bahwa ketika Yunus melihat apa yang terjadi pada bangsa Niniwe ia merasa sama sekali tidak senang. ${ }^{18}$ Kasih Allah kepada Niniwe dan perubahan rencana Allah terhadap bangsa ini menimbulkan kemarahan dan kekesalan yang sangat besar di hati Yunus. Kekesalan dan kemarahan Yunus ini berbanding terbalik dengan tujuan Pedagogi itu sendiri. Sebagai seorang guru, Yunus berhasil melakukan transformasi karakter terhadap bangsa Niniwe, namun keberhasilannya inilah kunci dari kemarahannya.

Ayat ke-5 menggambarkan tindakan Yunus sebagai ekspresi dari rasa kekesalannya. Yunus keluar dari kota itu dan mengambil tempat yang strategis baginya untuk dapat melihat apa yang terjadi dengan kota itu. Menurut Kramer, aksi Yunus pergi ke luar dari kota disebabkan ia masih berharap bahwa Allah akan menghukum Niniwe. Yunus menantikan apa yang akan terjadi pada kota itu sementara ia bertindak sebagai penonton yang menyaksikan peristiwa-peristiwa yang akan terjadi pada Niniwe tanpa mencoba ambil bagian dalam pergumulan orang Niniwe dan tidak merasa diri solider dengan mereka. ${ }^{19}$ Di tempat itu, mendirikan sebuah pondok agar dapat duduk di bawah naungannya. Dalam beberapa versi terjemahan, pondok ini digunakan untuk menaunginya, atau membayanginya. Menurut Kramer, Yunus mendirikan pondok ini melindungi dirinya dari panas terik dan sebagai tempat bernaung. ${ }^{20}$

Dalam ayat ke 6-8 menceritakan bahwa Allah menumbuhkan sebuah pohon קִ jerak bagi Yunus untuk menaunginya. Bahasa asli dari pohon ini adalah

\footnotetext{
18 Kramer, Tafsiran Alkitab: Kitab Yunus, $N p$.

${ }^{19}$ Kramer, Tafsiran Alkitab: Kitab Yunus, $\mathrm{Np}$.

20 Ibid, Np.
} 
Volume 7 Nomor 2, Desember 2021

(Kikayon) yang diterjemahkan langsung oleh para rabi tetap sebagai Kikayon. ${ }^{21}$ Intelinear Bible menterjemahkannya sebagai plant atau tanaman tanpa identifikasi lebih dalam meskipun pada akhirnya diarahkan kepada castor-oil plant atau pohon jarak, meskipun dalam penterjemahan sendiri para ahli hanya menggunakan kata ( $a$ plant) perhaps castor-oil plant. Dalam KJV diterjemahkan sebagai gourd atau labu manis atau kendur. ${ }^{22}$ Ada kemungkinan memang Kikayon merupakan tanaman khusus yang hanya ada di dunia Timur Tengah kuno masa itu atau memang masih satu spesies jarak yang tampilannya berbeda dengan jarak pada umumnya di Indonesia. Dan diterjemahkan ke dalam Bahasa Indonesia sebagai pohon jarak.

Pohon ini adalah pohon ajaib, karena ia bertumbuh dalam satu malam dan langsung besar dalam satu malam itu juga. Pohon itu bertumbuh di atas Yunus, untuk menaungi dia atau membayangi dia dan memerdekakan atau membebaskan dia dari rasa dukacitanya. Versi RSV menyampaikan hal yang berbeda, bahwa pohon itu menyelamatkan (save) dia dari rasa ketidaksenangannya. Dan pohon ini menjadikan dia sangat bersukacita, KJV menuliskan tentang sukacita yang besar, kegembiraan yang sangat besar (very much elated, $M L$ ), menyenangkan dan sangat bersukacita (LB), luar biasa senang (extremely happy about the plant, NASU dan NAS). Pohon itu sendiri dapat bertumbuh dengan cepat dan mencapai tinggi 3-5 m, mempunyai daun besar dan memberi naungan yang enak. Tuhan menumbuhkan pohon ini agar dapat melepaskan dia dari kekesalannya. ${ }^{23}$ Namun, pohon ini tidak berumur panjang. Karena keesokan harinya, atas penentuan Tuhan, pohon ini pun layu dan mati (LB). Allah mengirim ulat yang meratakan (KJV), menyerang (ML), memakan (LB), mengunyah (NIV). Tidak berhenti di situ saja, masih atas penentuan Tuhan, maka bertiuplah angin timur yang panas terik dan matahari yang menyakiti kepala Yunus. Angin Timur ini adalah angin yang bertiup dari padang gurun, sangat panas, belum lagi matahari yang menyengat. Akibatnya lesulah ia, rebah dan berharap (TB, KJV), menginginkan (ML), meminta (RSV), memohon (NAS), memohon (ASV, requested) supaya ia mati saja. Ia juga mengatakan bahwa "lebih baik aku mati daripada hidup", versi LB mengatakan bahwa "mati adalah lebih baik daripada ini".

\section{Pedagogi Allah Terhadap Yunus Melalui Analogi Niniwe Dan Pohon Jarak}

Pada bagian ini, penulis menyoroti beberapa teks kunci pengalaman sekaligus dialog antara Allah dan Yunus melalui pohon jarak. Dialog dan pengalaman bersama dengan Allah dan pohon jarak ini adalah bentuk pengajaran karakter atau pedagogi

${ }^{21}$ Philip J. Donnelly, An Introduction to the Books of the Old Testament, Thought, vol. 11, 1936.

${ }^{22}$ Leslie C Allen, The Books of Joel, Obadiah, Jonah, and Micah (Grand Rapids: Wm. B. Eerdmans Publishing, 1976, Np).

${ }^{23}$ Ibid, Np. 
yang Allah lakukan terhadap Yunus. Dalam ayat ke-4 ada dialog tentang kelayakan dari kemarahan Yunus yang menjadi ide dari artikel ini. "Layakkah engkau marah?". Jika diperhatikan, pertanyaan yang muncul dalam ayat ke-4 ini ternyata sama persis dengan pertanyaan yang muncul pada ayat ke-9, baik dalam versi terjemahan maupun bahasa aslinya. Istilah "Marah" di sini dalam bahasa aslinya berarti geram, terbakar, menyala, dll. Dari beberapa versi terjemahan lain, dapat diketahui bahwa ternyata, selain Allah mempertanyakan tentang kelayakan Yunus untuk marah, Allah juga mempertanyakan tentang apakah Yunus memiliki alasan yang baik untuk menjadi marah (versi ML dan NAS).

Menurut Kramer, pertanyaan ini bukanlah bentuk kemarahan Tuhan, juga bukan cara Allah mempersalahkan Yunus, tetapi suatu bentuk pertanyaan yang merangsang Yunus untuk berpikir. Upaya Allah merangsang Yunus berpikir dan mengambil keputusan layak atau tidak terhadap tindakan "marah"nya menjadi ide utama Pedagogi pohon jarak ini. Jadi jawaban Allah pada Yunus yang muncul dalam bentuk pertanyaan ini sebenarnya adalah cara agar Yunus berpikir dan memutuskan sendiri apa yang seharusnya ia lakukan. Yaitu, "Layakkah engkau marah?".

Allah dalam peristiwa ini berperan sebagai pendidik dan Yunus mengambil peran sebagai murid. Tujuan Allah sebagai pendidik di sini adalah mengubah kerangka berpikir Yunus tentang Kasih Allah yang universal sekaligus mengubah karakter Yunus untuk mau menerima fakta tentang kasih Allah itu dan mau berbagi kasih Allah kepada semua manusia sekalipun bagi Yunus orang-orang itu tidak pantas menerima kasih Allah. Allah secara langsung menggunakan analogi Pohon Jarak dalam pengalaman Yunus untuk diperbandingkan dengan Niniwe, kota besar tersebut. Keduanya sama-sama mengasihi, Allah mengasihi Niniwe sementara Yunus mengasihi Pohon Jarak. Allah mengajari Yunus tentang kasih Allah terhadap Niniwe melalui pengalaman Yunus dengan Pohon Jarak. Metode ini dalam Pendidikan dikenal dengan experiential learning.

Dalam Pendidikan, metode experiential learning merupakan pendekatan yang mampu memberikan efek paling besar bagi para peserta didik. Bahkan menurut Sulistian, hasil yang diperoleh melalui experiential learning efektifitasnya adalah Sembilan kali lebih besar dari pada metode pembelajaran biasa. Hal ini dikarenakan metode ini sanggup menggiring orang pada pengalaman yang tidak terlupakan, penuh tantangan dan aplikatif. ${ }^{24}$ Melalui metode ini, peserta didik diarahkan untuk mengalami sendiri topik yang sedang dipelajari. ${ }^{25}$

24 Ratna dan Erlinda Manaf Mahdi Sulastami, Universal Inteligence (Jakarta: Gramedia Pustaka Utama, 2019), Np.

25 Dwi Ningwang Agustin, “Serambi Guru: Bukan Sekadar Mengajar” (Gresik: Semesta Aksara, 2021), Np. 
Volume 7 Nomor 2, Desember 2021

Pengalaman Yunus Bersama pohon Jarak menjadi kunci cara Tuhan dalam mengajari Yunus. Inilah contoh pedagogi Allah terhadap Yunus. Allah mengajari Yunus bukan dengan kata-kata, tapi dengan pengalaman terlebih dahulu, supaya Yunus menjadi benar-benar mengerti tentang apa yang sebenarnya sedang Tuhan pikirkan tentang Niniwe dan Yunus pikirkan tentang Niniwe. Bagaimana dengan kasih Allah pada Niniwe diperbandingkan dengan kasih Yunus terhadap pohon jarak.

Setelah Tuhan merasa bahwa pengalaman ini cukup, maka Ia kemudian memberikan pengajaran kepada Yunus. Dalam ayat ke-9, diskusi atau dialog antara Tuhan dan Yunus dimulai, saat-saat di mana Allah mulai mengajari Yunus dengan kata-kata. Allah bertanya lagi seperti pertanyaan yang sudah muncul di ayat ke 4, "Layakkah engkau marah?”. Tapi kali ini Allah bertanya tentang pohon itu. Jawaban Yunus yang mengungkapkan gambaran kekesalannya muncul. Yunus menjawab, "selayaknyalah aku marah sampai mati." Kalau versi lain, menyatakan bahwa "aku memang pantas untuk marah bahkan sampai mati (KJV), aku punya alasan yang bagus untuk marah, cukup untuk mati (ML).

Yunus menjawab bahwa ia memang layak untuk marah, bahkan sampai mati, sepertinya Yunus berbicara di sini tanpa berpikir panjang terlebih dahulu, padahal dalam ayat ke-4, Yunus sama sekali tidak memberi jawaban. Van Der Woude sebagaimana dikutip oleh Kramer menafsirkan bahwa sebenarnya ayat ke 5-9 merupakan flash back dari cerita yang terjadi sebelum ayat 1-4. Jadi ayat 6-9 merupakan latar belakang dari percakapan antara Tuhan dan Yunus dalam ayat 1-4. Inilah yang menjadi alasan mengapa Yunus tidak menjawab pertanyaan pada ayat ke4. Karena ternyata ia teringat dengan kejadian dalam ayat ke 5-9, dan ia sangat malu. ${ }^{26}$ Menyoroti ayat 9 dan 10, jika mengikuti dari Van der Woud kedua ayat ini merupakan lanjutan dari ayat 1-4. Saat yang menurut Kramer sebagai saat di mana Allah mengikhtisarkan tentang peristiwa-peristiwa yang telah terjadi dan menarik kesimpulan. ${ }^{27}$

Menurut penulis, inilah puncak dari pengajaran Allah kepada Yunus. Allah membuat perbandingan antara kedua peristiwa itu, antara kasih yang Allah miliki kepada Niniwe, bangsa besar yang tidak bisa membedakan tangan kanan dan tangan kiri atau tidak bisa membedakan mana yang baik dan jahat dengan kasih Yunus kepada pohon jarak yang tumbuh dan besar dalam semalam dan mati dalam semalam juga. Ketegangan dari cerita ini terjadi antara Yunus, manusia biasa, yang bisa begitu mengasihi pohon jarak yang berumur sangat pendek, padahal bukan dia yang menanam, bukan dia yang menyiram dan Allah, yang Maha Kasih, yang mengenal Niniwe dengan begitu baik, sampai orang perorang. Niniwe merupakan sebuah

\footnotetext{
${ }^{26}$ Kramer, Tafsiran Alkitab: Kitab Yunus, Np.

27 Ibid, Np.
} 
Volume 7 Nomor 2, Desember 2021

bangsa yang menjadi target Pedagogi Yunus. Allah memberikan perintah agar Yunus pergi memberitakan berita penghukuman dengan tujuan agar terjadi transformasi karakter pada orang-orang Niniwe.

Tranformasi karakter orang-orang Niniwe menjadi alasan kuat Allah untuk membatalkan hukuman kepada Niniwe. Dengan berbagai drama yang terjadi, Yunus akhirnya pergi ke Niniwe menyampaikan pesan Allah. Sebagai seorang guru, Yunus sangat berhasil dalam Pedagoginya. Namun keberhasilannya ini membuat Yunus kesal dan marah besar sampai ingin mati. Hal ini membuat Allah mengambil Langkah Pedagogi terakhir dalam kisah Yunus yaitu Pedagogi Pohon Jarak. Yunus mengasihi pohon yang "tumbuh dengan sendirinya" (dibaca atas seizin Allah) ini karena memberikan keteduhan padanya. Dan merasa marah serta putus asa karena pohon tersebut mati. Pada saat yang sama, dalam dialog tersebut Allah ingin mengajari Yunus bahwa Niniwe juga merupakan bangsa yang Allah kasihi dan Allah mau mereka berubah sehingga Allah dapat rencana-Nya menghukum mereka.

Pertanyaan yang Allah berikan merupakan pertanyaan pedagogis dan menjadi formula pedagogi Allah terhadap Yunus, dengan mengorek kekonsekwenan dalam diri Yunus tentang kasihnya terhadap pohon dan terhadap kota. Sebuah pertanyaan yang menurut Kramer tidak membutuhkan jawaban, ${ }^{28}$ namun bagi penulis memerlukan perenungan yang mendalam dalam rumusan "Layakkah engkau marah?" Perenungan menjadi metode pembelajaran yang penting bukan untuk aspek kognitif namun lebih kepada aspek spiritual dan mental seseorang dalam bentuk Pedagogik.

\section{Kesimpulan}

Pedagogi merupakan bagian yang sangat penting dalam pengajaran karena bertujuan melakukan transfomasi karakter dalam diri siswa didik. Dalam hal ini, guru Pedagog berperan sebagai seorang transformator. Karena itu, keberhasilan guru Pedagog terletak pada terjadinya perubahan karakter siswa ke arah yang lebih baik dan/atau dewasa. Dalam kasus Yunus, Yunus justru menyesal dan marah karena perubahan karakter yang terjadi di antara orang-orang Niniwe. Yunus marah karena orang-orang Niniwe menginsafi kesalahan mereka dan bertobat sehingga Allah batal menghukum mereka. Untuk itu, Allah sebagai pengutus Yunus memiliki satu tugas lain bagi nabi-Nya ini. Sebuah tugas yang sama yaitu Pedagogi terhadap sang nabi. Pedagogi Allah dilakukan melalui experiencial learning berupa pengalaman Yunus bersama Pohon Jarak yang penulis sebut dengan Pedagogi Pohon Jarak. Pengalaman ini memberi kesempatan untuk Yunus berrefleksi antara kasih Allah yang besar bagi Niniwe dan kasihnya yang besar bagi Pohon Jarak. Meskipun kisah ini perjalanan nabi 
Volume 7 Nomor 2, Desember 2021

Yunus tidak memiliki akhir yang jelas namun para pembaca dapat menentukan sendiri akhir dari kisah Yunus karena kritik yang sama disampaikan kepada para pembaca.

\section{Referensi}

Agustin, Dwi Ningwang. "Serambi Guru: Bukan Sekadar Mengajar." Gresik: Semesta Aksara, 2021.

Allen, Leslie C. The Books of Joel, Obadiah, Jonah, and Micah. Grand Rapids: Wm. B. Eerdmans Publishing, 1976.

- - - The Books of Joel, Obadiah, Jonah, and Micah. Grand Rapids: Wm. B. Eerdmans Publishing, 1976.

Alter, Robert. The Art of Biblical Narrative. New York: basic Books, 2010.

Baxter, J Sidlow. Explore The Book: A Survey and Study of Each Book From Genesis. Grand Rapids: Zondervan, n.d.

Dasar, Direktorat GTK Pendidikan. MODUL BELAJAR MANDIRI CALON GURU Pegawai Pemerintah Dengan Perjanjian Kerja Pedagogi, 2021.

Donnelly, Philip J. An Introduction to the Books of the Old Testament. Thought. Vol. 11, 1936.

Jobling, David. The Sense of Biblical Narrative: Structural Analyses in the Hebrew Bible II. England: Sheffield Academic Press, 1987.

Kramer, A. Th. Tafsiran Alkitab: Kitab Yunus. Jakarta: BPK Gunung Mulia, 2003.

Morissan. Metode Penelitian Survei. Rawamangun: Kencana, 2012.

Nurdyansyah, and Eni Fariyatul Fahyuni. Inovasi Model. Nizmania Learning Center, 2016.

Permana, Rahmat. Teori Dan Praktik Pendidikan Jasmani Di Perguruan Tinggi. Tasikmalaya: Edu Publisher, 2020.

Subandi. "Qualitative Description as One Method in Performing Arts Study." Harmonia, no. 19 (2011): 173-179.

Sugiyono. Metode Penelitian Kuantitatif, Kualitatif, Dan $R$ \& D. Bandung: Alfabeta, 2013.

Sulastami, Ratna dan Erlinda Manaf Mahdi. Universal Inteligence. Jakarta: Gramedia Pustaka Utama, 2019.

Williamson, Peter S. Catholic Principles for Interpreting Scripture. Catholic Biblical Quarterly. Vol. 65, 2003.

Yuberti. Teori Pembelajaran Dan Pengembangan Bahan Ajar Dalam Pendidikan, 2014. 